\title{
Measuring unintended pregnancies in postpartum Iranian women: validation of the London Measure of Unplanned Pregnancy
}

S. Roshanaei, ${ }^{1}$ A. Shaghaghi, ${ }^{1}$ M.A. Jafarabadi ${ }^{2}$ and A. Kousha ${ }^{1}$

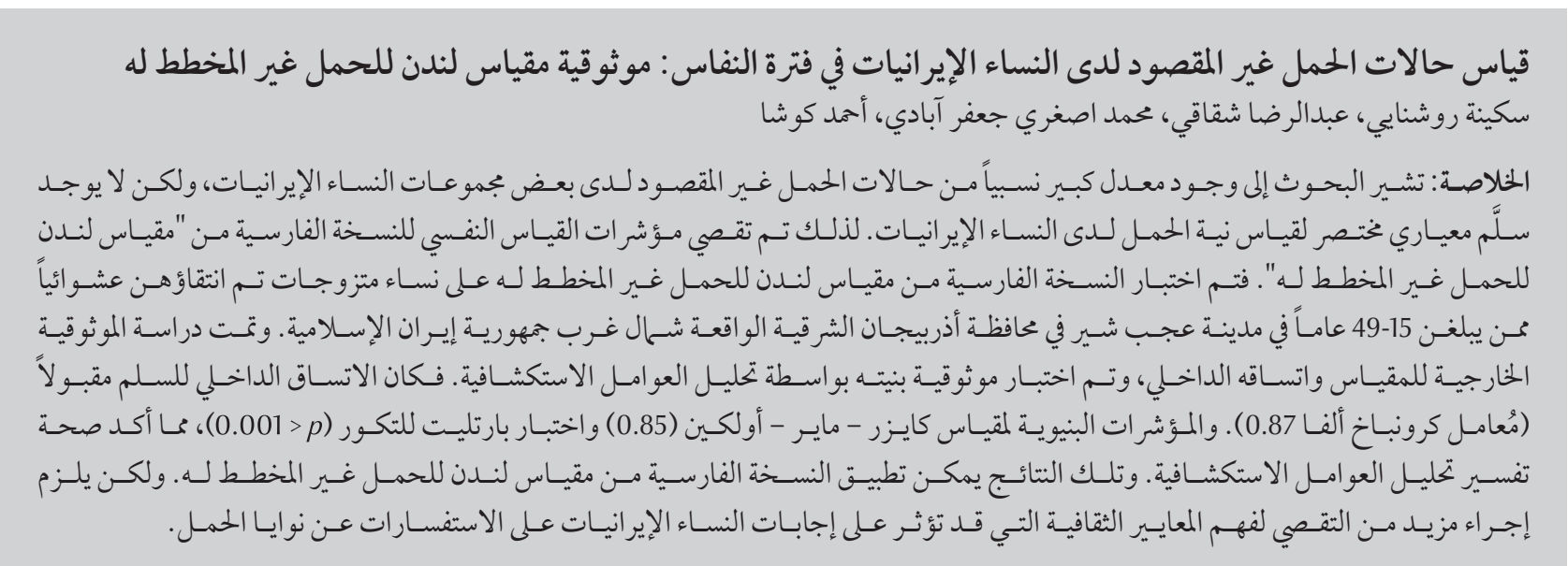

ABSTRACT Research suggests a relatively sizable rate of unintended pregnancies in some subgroups of Iranian women, but there is no concise, standard scale to measure the pregnancy intention of Iranian women. Therefore, the psychometric properties of the Persian version of the London Measure of Unplanned Pregnancy (LMUP) were investigated. The Persian version of the LMUP was tested on randomly selected married women aged 15-49 years in the city of Ajabshir, East Azerbaijan province, north-west of Islamic Republic of Iran. The scale's face validity and internal consistency was examined and its construct validity was tested by exploratory factor analysis. The internal consistency of the scale was acceptable (Cronbach alpha coefficient 0.87). Structural indicators of the Kaiser-MeyerOlkin measure $(0.85)$ and Bartlett test of sphericity $(P<0.001)$ verified interpretability of the exploratory factor analysis output. Applicability of the Persian version of the LMUP is accepted. Further investigation is needed to understand cultural norms that might influence Iranian women's responses to queries about pregnancy intentions.

Mesure des grossesses non désirées chez des femmes iraniennes en postpartum : validation de l'échelle London Measure of Unplanned Pregnancy

RÉSUMÉ Les travaux de recherche suggèrent que le taux de grossesses non désirées dans certains sous-groupes de femmes iraniennes est relativement important. Toutefois, il n'existe pas d'échelle concise et normalisée de mesure de l'intention de grossesse chez les femmes iraniennes. Par conséquent, les propriétés psychométriques de la version en langue perse de l'échelle London Measure of Unplanned Pregnancy ont été étudiées. La version en langue perse de l'échelle a été testée auprès de femmes mariées âgées de 15 à 49 ans et sélectionnées aléatoirement dans la ville d'Ajabshir, dans la province de l'Azerbaïdjan oriental, au nord-ouest de la République islamique d'Iran. La validité apparente de l'échelle et sa cohérence interne ont été examinées. Sa validité conceptuelle a été testée par une analyse des facteurs exploratoires. La cohérence interne de l'échelle était acceptable (coefficient alpha de Cronbach : 0,87). Des indicateurs structuraux de la mesure de Kaiser-MeyerOlkin $(0,85)$ et le test de sphéricité de Bartlett $(P<0,001)$ ont permis de vérifier l'interprétabilité du résultat de I'analyse factorielle exploratoire. L'applicabilité de la version en langue perse de l'échelle a été acceptée. Des recherches supplémentaires sont requises pour comprendre les normes culturelles qui pourraient influer sur les réponses des femmes iraniennes aux questions sur l'intention de grossesse. 


\section{Introduction}

Maternal mortality risk is highly dependent on the health conditions that pregnant women experience during their pregnancy and the care that they receive. Unplanned pregnancies can pose serious threats to the health of mothers, their children and families, and to the wider community. Therefore, reduction of the number of unplanned conceptions has been highlighted in many global public health policy mandates (1). Even in optimal conditions, unplanned pregnancies may have poorer outcomes such as abortion or obstetric complications than those that are scheduled (1). Women in developing countries are the most affected by the consequences of unintended pregnancies. Of 80 million unplanned conceptions that occurred in developing countries in 2012 an estimated 30 million resulted in unwanted births, 40 million in abortion and 10 million in miscarriages $(2,3)$. An estimated $79 \%$ of unintended pregnancies were due to the fact that worldwide 222 million women in their fertile years had unmet needs for family planning services (3).

To meet the health needs for family planning services the intentions of women to have the desired number of children, and at the right time, must be closely studied. Research evidence that provides baseline information about the current status of mothers regarding their needs for better family planning services is non-existent or meagre in many developing countries. Most current estimates of the levels of unintended pregnancies in developing countries are based on questions used in the national demographic and health surveys (4). Application of non-standard procedures to determine unmet needs of reproductive health, however, might put these figures under scrutiny.

The London Measure of Unplanned Pregnancy (LMUP) is a relatively new tool for measuring the degree of pregnancy intention of a current or recent pregnancy (5). It was developed in the United Kingdom and has subsequently been validated for use in other countries $(2,6-9)$. The measure's simplicity and conciseness and also its widespread application to measure unintended pregnancies worldwide, means that it is a suitable method to assess unintended pregnancies. The questions in the scale cover contraceptive use, desire, intention and timing to have a baby, discussions with partner and pre-conception preparation (5).

To the best of our knowledge this scale has not been validated for use by Persian-speaking women and main aim of this study was to identify the psychometric properties of the translated LMUP to assess its applicability for Iranian women of childbearing age. Despite research evidence revealing a relatively sizable rate of unintended pregnancies in a number of subgroups of Iranian women (10), there is no concise, standard scale to measure the intention of Iranian women regarding their pregnancies. The translated questionnaire could assist researchers who wish to study this issue using an internationally recognized tool and ensure that their findings are comparable with studies in other parts of the world.

\section{Methods}

\section{The London Measure of Unplanned Pregnancy}

The LMUP is composed of 6 questions, each question scored from 0 to 2 (5) (Box 1). The total LMUP score, which is a continuous score from 0 to 12 , represents pregnancy intention and therefore an increase in the score indicates a higher degree of pregnancy intention.

\section{Box 1 Questions of the original version of the London Measure of Unplanned Pregnancy (24)}

Question 1. At the time of conception:

0 Always used contraception

1 Inconsistent use

2 Not using contraception

Question 2. In terms of becoming a mother:

0 Wrong time

1 OK but not quite right

2 Right time

Question 3. Just before conception:

0 Did not intend to become pregnant

1 Changed intentions

2 Intended to get pregnant

Question 4. Just before conception:

0 Did not want a baby

1 Mixed feelings about having a baby

2 Wanted a baby

Question 5. Before conception:

0 Had never discussed children

1 Discussed but no firm agreement

2 Agreed pregnancy with partner

Question 6. Before conception:

0 No actions

1 Health preparations $\left(1\right.$ action $\left.^{\mathrm{a}}\right)$

2 Health preparations $\left(\geq 2\right.$ actions $\left.^{\mathrm{a}}\right)$

${ }^{a}$ Health preparations included the following actions: taking folic acid supplements, stopping or reducing smoking, stopping or reducing alcohol consumption, healthy eating, and seeking medical advice before conception. 
The scoring method of pregnancy intention avoids dichotomization of pregnancies into planned and unplanned and allows ambivalences between these states. One of the recommendations in interpretation of the LMUP score is to consider scores of $0-3$ as an indicator of unplanned pregnancy, scores of 4-9 to represent uncertain states and scores of 10-12 as planned pregnancy (7).

\section{Translation of the questionnaire}

A standard translation and back translation procedure was applied. As the first step the original English-language scale was translated into Persian by a native professional and by a non-professional speaker of the Persian language who had a good knowledge of English. In the second step the translated questionnaire was independently retranslated to the original language by 2 professional academic members of Tabriz University of Medical Science who were fluent in the use of academic English. The retranslated versions were then compared with the original questionnaire and the final translated version was agreed upon by consensus at the third step.

The overall content validity of the Persian version of the LMUP was examined by a group of 9 experts in the field to ensure its consistency with the explained purpose of the scale. Every reviewer was asked to rate independently the relevance of the items in the translated LMUP based on a 4-point Likert scale (completely relevant, relevant, slightly relevant, not relevant) and the calculated content validity index (0.83) was in the vicinity of the acceptable range $(>0.79)(11)$.

The original LMUP was designed for self-completion but, considering the level of literacy in the women of the study location and in line with previously conducted studies $(2,6)$, the translated version was adapted in a way that made its administration by an interviewer possible.

To probe comprehensibility of the translated version and lucidity of the wordings used, the scale was also pretested through cognitive interviews with 20 women who had delivered their child in the last 24-48 hours at the study location. However, no major suggestions for changes were made that would affect the clarity of the questionnaire. The only minor modification from the original LMUP was rewording of the items to refer explicitly to a husband rather than to husband or partner; this was done to comply with the cultural context of the study population. Thus, the face validity of the translated scale, i.e. its appropriateness to be used for the study purpose and content area, was confirmed.

\section{Validation of the translated LMUP scale}

\section{Study participants}

Validation of the LMUP to be used in Persian-speaking women was a part of a larger cross-sectional population-based study of the unmet needs for family planning services among representative samples of Iranian women. Married women aged 15-49 years who had given birth within the last 6 months were contacted to field-test the translated Persian version of the LMUP.

The participants were recruited randomly from the list of registered deliveries in the recent 6 months in the only referral hospital accessible as an approved delivery facility within the city of Ajabshir, East Azerbaijan province, north-west of the Islamic Republic of Iran. There were 520 deliveries in total from September 2013 to March 2014, of which 320 were related to those women living in the nearby rural areas and 200 to the women of urban areas.

Quota sampling was used to ensure that the sample composition matched the ratio of rural and urban women who had delivered their child in the studied hospital. By this method 76 (38.5\%) mothers from urban areas and 158 (61.5\%) from rural areas $(n=234)$ who delivered their child in the last 6 months were recruited. Only those women who had delivered a healthy child and were living with their husband as a permanent resident in the study area were eligible to be included. The women who had stillbirths, those who lost their child due to accident or illness and women who were widowed or separated from their husbands were excluded.

\section{Data collection}

Face-to-face interviews was conducted with the participants at home after explaining the study objectives to them and obtaining their written informed consent. Any selected woman who was not found at the given address or refused to participate in the study was replaced by another woman randomly selected from the list of eligible respondents. Questions in the translated LMUP were asked by the data collector and the respondents' answers were documented.

\section{Ethical approval}

This study was approved by the medical research ethics committee at Tabriz University of Medical Sciences (approval number and date: 5/4/7545, 6 January 2014). Written informed consent was obtained for the all study respondents. Anonymity of the participants and confidentiality of the collected data and their right to withdraw from the study without providing any reason was also explained.

\section{Data analysis}

The construct validity of the translated LMUP, i.e. verification of the proposed construct measurement by the selected scale items, was assessed by exploratory factor analysis using SPSS, version 15. This method examines inter-relationships among the scale items and probes the degree of variation among items to justify their presence in the instrument. For the purpose of this study, principle component analysis was applied to determine the items' suitability in the translated scale.

Asapart ofexploratoryfactoranalysis process, sampling adequacy was decided based on the Kaiser-Meyer-Olkin 
measure which generally should be above $0.6-0.7$ for the output of the analysis to be interpretable (12). Measures of sampling adequacy assess the degree of correlation among scale items in the exploratory factor analysis correlation matrix. This measure is applicable to determine adequacy of the sampling for psychometric scale evaluation.

Bartlett test of sphericity was also applied to test whether the correlation matrix of scale items can be elucidated by exploratory factor analysis (13). The test measure must be significant $(P<$ $0.05)$ to confirm a relationship among the scale items in the correlation matrix (14). Since the appropriate number of factors $(n=6)$ to explain unplanned pregnancy was determined a priori in the original LMUP, no attempt was made to determine the appropriate number of factors for retention in the translated version of the scale. However, corrected item-to-total correlation index that represents whether an item in the scale is correlated with the remaining items was used to decide which items could provide meaningful information in explaining the proposed construct. Generally a minimum value of 0.4 is required for corrected item-tototal correlation index of an item to be kept in the scale (15).

Cronbach alpha coefficient was also calculated to assess the internal consistency reliability of the translated LMUP and 0.7 was considered as the cut-off point for acceptable reliability (16).

\section{Results}

The total scores of the study participants indicated a skewed asymmetrical distribution on the LMUP: 155 (66.2\%) of the respondents scored 10-12, meaning that they had had a planned pregnancy; 53 (22.6\%) scored 4-9, indicating that they were in an ambivalent state of mind; and 26 (11.1\%) scored $0-3$, reflecting that they had experienced an unplanned pregnancy.

The distribution of women at the different cut-offs of LMUP score, by age group, number of children and residential area are presented in Table 1. Most of the unplanned pregnancies (57.7\%) were reported by the older women $(\geq$
35 years) and those with at least 2 or more current children (80.8\%). An ambivalent state of mind about the recent pregnancies was also seen mostly among the women aged 20-34 years (75.5\%) and those with 1-2 children (77.4\%).

The sample-size-adjusted rate of unplanned pregnancy in the primaparous women of the study was 0.12 , while this rate in the multiparous women with 1 child was 0.02 , with 2 children was 0.09 , with 3 children was 0.40 and in women with $\geq 4$ children it was 0.63 .

Figure 1 shows the mean age of the women presented according to the LMUP scores of the studied women in 3 groups (unplanned pregnancy, ambivalent and planned pregnancy). The mean age of the women with scores $0-3$ on the LMUP was 34.0 years, in those scoring 4-9 it was 29.0 years and in those scoring 10-12 it was 25.2 years. The differences in the mean age of the women in different LMUP score groups were statistically significant $(P$ $<0.001)$ and was higher in women who reported having an unplanned pregnancy.

\begin{tabular}{|c|c|c|c|c|c|c|c|c|}
\hline \multirow[t]{3}{*}{ Variable } & \multicolumn{6}{|c|}{ LMUP score } & \multicolumn{2}{|c|}{ Total } \\
\hline & \multicolumn{2}{|c|}{ 0-3 } & \multicolumn{2}{|c|}{ 4-9 } & \multicolumn{2}{|c|}{$10-12$} & \multirow[b]{2}{*}{ No. } & \multirow[b]{2}{*}{$\%$} \\
\hline & No. & $\%$ & No. & $\%$ & No. & $\%$ & & \\
\hline Total & 26 & 100.0 & 53 & 100.0 & 155 & 100.0 & 234 & 100.0 \\
\hline \multicolumn{9}{|c|}{ Age group (years) } \\
\hline $15-19$ & 1 & 3.8 & 1 & 1.9 & 46 & 29.7 & 48 & 20.5 \\
\hline $20-34$ & 10 & 38.5 & 40 & 75.5 & 101 & 65.2 & 151 & 64.5 \\
\hline$\geq 35$ & 15 & 57.7 & 12 & 22.6 & 8 & 5.2 & 35 & 15.0 \\
\hline \multicolumn{9}{|c|}{$\begin{array}{l}\text { No. of children before } \\
\text { last delivery }\end{array}$} \\
\hline 0 & 3 & 11.5 & 4 & 7.5 & 18 & 11.6 & 25 & 10.7 \\
\hline 1 & 2 & 7.7 & 23 & 43.4 & 70 & 45.2 & 95 & 40.6 \\
\hline 2 & 8 & 30.8 & 18 & 34.0 & 60 & 38.7 & 86 & 36.8 \\
\hline 3 & 8 & 30.8 & 5 & 9.4 & 7 & 4.5 & 20 & 8.5 \\
\hline$\geq 4$ & 5 & 19.2 & 3 & 5.7 & 0 & 0.0 & 8 & 3.4 \\
\hline \multicolumn{9}{|c|}{ Area of residence } \\
\hline Urban & 11 & 42.3 & 21 & 39.6 & 44 & 28.4 & 76 & 32.5 \\
\hline Rural & 15 & 57.7 & 32 & 60.4 & 111 & 71.6 & 158 & 67.5 \\
\hline
\end{tabular}




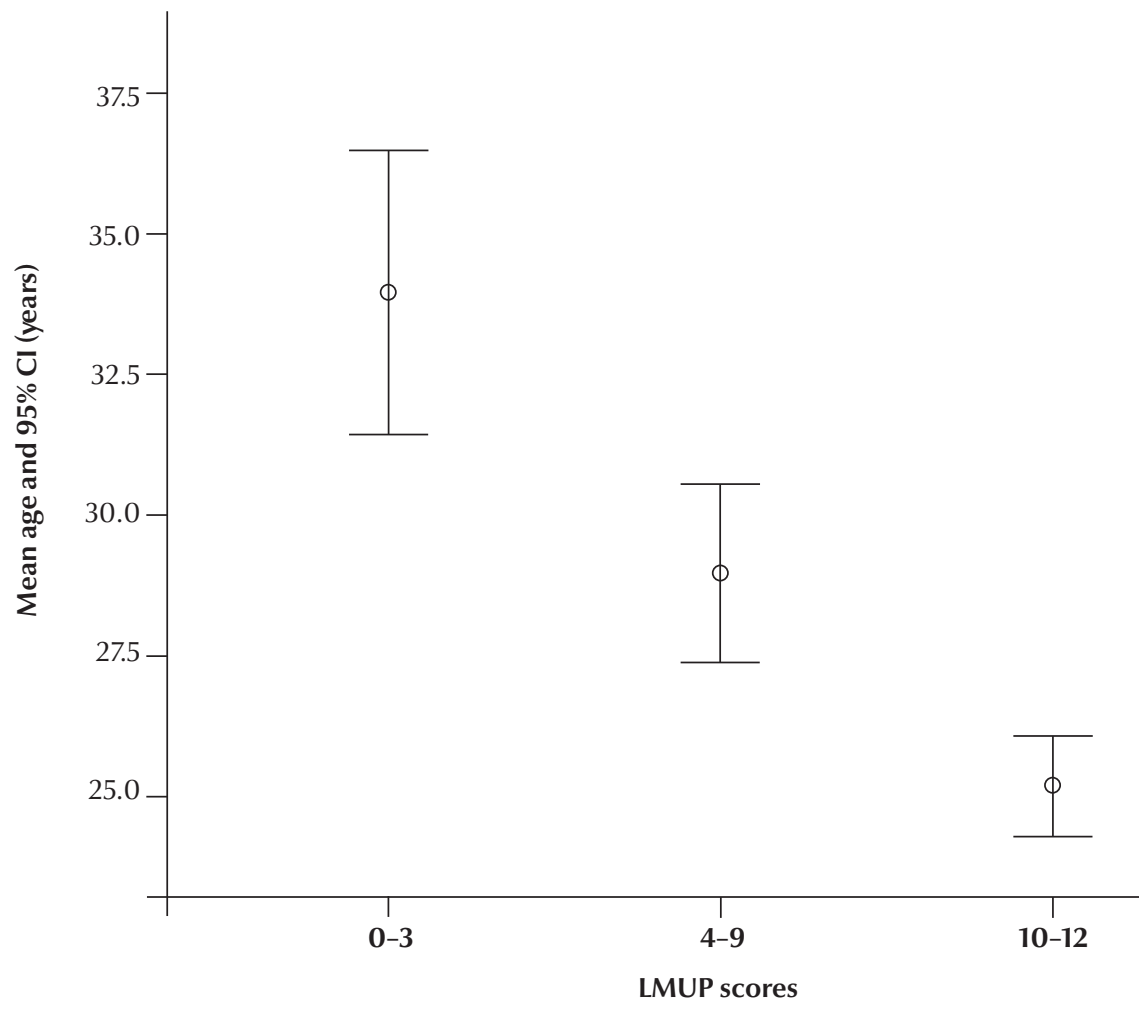

Figure 1 Mean age and 95\% confidence intervals $(\mathrm{Cl})$ of respondents by category of score on the London Measure of Unplanned Pregnancy (LMUP)

The sample-size-adjusted ratio of unplanned pregnancy in the studied women of urban areas (14.5\%) was higher than the women of rural areas (9.5\%); however, this difference was not statistically significant $(95 \% \mathrm{CI}:-0.8$ to $11.1 \%)$.

Structural indicators of the Kaiser-Meyer-Olkin measure $(0.85)$ and Bartlett test of sphericity $(P<0.001)$ verified the interpretability of the exploratory factor analysis output in this study. The corrected item-to-total correlation indices to decide on retention of the translated scale's items are shown in Table 2. Only item 6, which refers to the preparation for pregnancy by the study respondents, had a value $<0.4$ which suggests it was not correlated with the scale's other items to explain an unplanned pregnancy (16).

Internal consistency reliability of the translated version of the LMUP was also acceptable based on the Cronbach alpha coefficient which was calculated as 0.87 . retained in the translated version. Therefore, the researchers' overall judgement was in favour of acceptability and applicability of the Persian version of the LMUP in research studies to explore unintended pregnancies in Islamic Republic of Iran or in Persian-speaking populations.

Item 6, which refers to the measures that are generally adopted for pregnancy preparation, was not correlated with other items of the scale to disclose an unintended pregnancy. The main cause of this inconsistency with the acceptable fit range of item-tototal correlation index could be Iranian women's unfamiliarity with the concept of employing preparatory actions for pregnancy, such as taking folic acid, as is common in many countries of the world. Giving advice or encouragement to the women of childbearing ages to take appropriate actions for their pregnancy preparedness is not routine in the country's national health system.

Therefore, one suggestion might be keeping this item under scrutiny to check whether the observed lack of fit is the result of random bias. Otherwise, modification or excluding of item 6 from the Persian translated version of the LMUP will be inevitable if upcoming research evidence will approve its low contribution to the measurement of the intention. Before obtaining this research evidence, however, our suggestion is to keep the item in the scale, since even with the inclusion of all 6 items internal consistency reliability of the translated scale was admissible. Similar low item-to-total correlation for item

\begin{tabular}{lc}
\hline $\begin{array}{l}\text { Table } 2 \text { Corrected item-to-total correlation indices of the } \mathbf{6} \text { items in the Persian } \\
\text { version of the London Measure of Unplanned Pregnancy }\end{array}$ \\
\begin{tabular}{lc} 
Item & Item-to-total correlation indices \\
Contraception & 0.52 \\
Timing & 0.70 \\
Intention & 0.89 \\
Desire & 0.89 \\
Partner & 0.78 \\
Preparation & 0.36 \\
\hline
\end{tabular}
\end{tabular}


6 was reported in other studies $(6,7)$, which may explain the incongruity of preparatory measures for pregnancy with the childbearing intentions of mothers in some countries or population subgroups.

Some limitations of the study should be noted. Several studies (17-22) have suggested that post-delivery measures of pregnancy intention might be prone to bias since intention estimates may change over time. Such an error may even occur in cross-sectional or prospective measurement of pregnancy intendedness. Therefore the findings of post-delivery studies of pregnancy intentions should be interpreted by caution. The authors were aware of the effect that the selected 0-6 months range between delivery and completion of the questionnaire might have on the responses of the participants. The decision was made, however, to discount the effect of the emotions mothers may have about their delivered child due to the biological and hormonal changes at delivery.

Since residential area may have an effect on mothers' intentions regarding their pregnancies, due to factors such as differences in literacy level, occupation and attitudes towards desired number of children, quota sampling was used to ensure that the sample composition matched the ratio of rural and urban women who had delivered their child in the studied hospital. A skewed representation of other traits such as socioeconomic status, however, cannot be ruled out. Sampling bias in this study was probably towards lower socioeconomic groups of women due to recruitment of the participants from the only government-run public hospital in the city; women of affluent families in the Islamic Republic of Iran generally prefer to birth their child in private hospitals. The second source of sampling bias was the exclusion of women who had had an abortion and who therefore have a higher probability of reporting an unintended pregnancy. Since abortion is illegal in the Islamic Republic of Iran and only permitted for medical purposes, we were unable to include these women in our study. But even with exclusion of women with abortion the reliability of the Persian-translated version of LMUP was satisfactory.

Due to the cross-sectional nature of the main study design we were not able to assess the precision of the measurement of the Persian version of the LMUP through test-retest reliability and administer the questionnaire on multiple occasions, as would be recommended (23). The other consideration in refraining from re-administration of the scale was the probability of contamination bias in a conservative traditional society that might potentially lead to mismatching of the answers over time since the original interview.

\section{Conclusions}

The LMUP was validated for first time to be used in the Islamic Republic of Iran or among Persian-speaking populations in the Eastern Mediterranean Region or wider world to measure the intention of women regarding their pregnancies. While the main study of the LMUP validation (5) was performed in a culturally different environment, the results of this study revealed that the scale might be applicable cross-culturally and this makes comparison of unintended pregnancies possible at the international level. Our study also indicated that retrospective application of the LMUP to measure pregnancy intentions could be considered in studies to measure the unmet needs of childbearing age women in the Islamic Republic of Iran. Further investigation is needed to understand Iranian women's attitude towards pregnancy and also cultural norms that might influence their decision as well as their responses to enquiries about pregnancy intentions.

\section{Acknowledgements}

We appreciate the cooperation of the mothers who participated in the survey, without whom this research project would never be conducted.

Funding: This study was financially supported by the Tabriz University of Medical Sciences (grant number: $5 / 53 / 4583$ ). The granting organization had no role in the study design, sample selection, analysis or interpretation of the data or writing and submission of the manuscript for publication.

Competing interests: None declared.

\section{References}

1. Wellings $\mathrm{K}$, Jones $\mathrm{KG}$, Mercer $\mathrm{CH}$, Tanton $\mathrm{C}$, Clifton $\mathrm{S}$, Datta $\mathrm{J}$, et al. The prevalence of unplanned pregnancy and associated factors in Britain: findings from the third National Survey of Sexual Attitudes and Lifestyles (Natsal-3). Lancet. $2013 \mathrm{Nov}$ 30;382(9907):1807-16. PMID:24286786

2. Hall J, Barrett G, Mbwana N, Copas A, Malata A, Stephenson J. Understanding pregnancy planning in a low-income country setting: validation of the London measure of unplanned pregnancy in Malawi. BMC Pregnancy Childbirth. 2013;13:200. PMID:24188251
3. Singh S, Darroch JE. Adding it up: costs and benefits of contraceptive services estimates for 2012. Geneva: Guttmacher Institute and United Nations Population Fund; 2012.

4. Tsui AO, McDonald-Mosley R, Burke AE. Family planning and the burden of unintended pregnancies. Epidemiol Rev. 2010;32(1):152-74. PMID:20570955

5. Barrett G, Smith SC, Wellings K. Conceptualisation, development, and evaluation of a measure of unplanned pregnancy. J Epidemiol Community Health. 2004 May;58(5):426-33. PMID:15082745 
6. Rocca $\mathrm{CH}$, Krishnan S, Barrett G, Wilson M. Measuring pregnancy planning: an assessment of the London Measure of Unplanned Pregnancy among urban, south Indian women. Demogr Res. 2010 Aug 6;23:293-334. PMID:21170147

7. Morof D, Steinauer J, Haider S, Liu S, Darney P, Barrett G Evaluation of the London Measure of Unplanned Pregnancy in a United States population of women. PLoS One. 2012;7(4):e35381. PMID:22536377

8. Cameron ST, Glasier A. Identifying women in need of further discussion about the decision to have an abortion and eventual outcome. Contraception. 2013 Jul;88(1):128-32. PMID:23218854

9. Backhausen MG, Ekstrand M, Tydén T, Magnussen BK, Shawe J, Stern J, et al. Pregnancy planning and lifestyle prior to conception and during early pregnancy among Danish women. Eur J Contracept Reprod Health Care. 2014 Feb;19(1):57-65. PMID:24229390

10. Erfani A. Levels, trends, and determinants of unintended pregnancy in iran: the role of contraceptive failures. Stud Fam Plann. 2013 Sep;44(3):299-317. PMID:24006075

11. Soeken KL. Validity of measures. In: Waltz C, Strickland OL, Lenz $\mathrm{E}$, editors. Measurement in nursing and health research. 4th ed. New York: Springer Publishing Company; 2010. pp. 163-203.

12. Netemeyer RG, Bearden WO, Sharma S. Scaling procedures: Issues and applications. London: Sage; 2003.

13. Hinton PR, Brownlow C, McMurray I, Cozens B. SPSS explained. London: Routledge; 2004.

14. Garson GD. Testing statistical assumptions. Asheboro (NC) Statistical Associates Publishing; 2012
15. Helms JE, Henze KT, Sass TL, Mifsud VA. Treating Cronbach's alpha reliability coefficients as data in counseling research. Couns Psychol. 2006;34(5):630-60.

16. Field A. Discovering statistics using IBM SPSS statistics. London: SAGE; 2013.

17. Poole VL, Flowers JS, Goldenberg RL, Cliver SP, McNeal $\mathrm{S}$. Changes in intendedness during pregnancy in a highrisk multiparous population. Matern Child Health J. 2000 Sep;4(3):179-82. PMID:11097505

18. Williams L, Abma J. Birth wantedness reports: a look forward and a look back. Soc Biol. 2000 Fall-Winter;47(3-4):147-63. PMID:12055692

19. Joyce T, Kaestner R, Korenman S. On the validity of retrospective assessments of pregnancy intention. Demography. 2002 Feb;39(1):199-213. PMID:11852837

20. Koenig MA, Acharya R, Singh S, Roy TK. Do current measurement approaches underestimate levels of unwanted childbearing? Evidence from rural India. Popul Stud (Camb). 2006 Nov;60(3):243-56. PMID:17060052

21. Weisberg E, Bateson D, Read C, Estoesta J, Lee C. Fertility control? Middle-aged Australian women's retrospective reports of their pregnancies. Aust N Z J Public Health. 2008 Aug;32(4):390-2. PMID:18782406

22. Guzzo KB, Hayford SR. Revisiting retrospective reporting of firstbirth intendedness. Matern Child Health J. 2014 Nov;18(9):21417. 10.1007/s10995-014-1462-7 PMID:24604625

23. Groth-Marnat G. Handbook of psychological assessment. Hoboken (NY): John Wiley; 2003. 